\title{
Making CNC Milling Router For Wood Material
}

\author{
Nika Saputra \\ nikachaniago@rocketmail.com
}

\begin{abstract}
Abstrak
Tujuan dari pembuatan proyek akhir ini adalah membuat mesin CNC MILLING ROUTER agar dapat membuat layout secara langsung Pada PCB dan dapat digunakan sebagai alat untuk cutting, engraving, marking pada objek kayu yang dapat membentuk objek 3 dimensi. Perancangan mekanik mesin CNC ini sebelumnya dibuat sketsa gambar pada kertas A3. Perancangan konstruksi mesin CNC meliputi bagian dasar, tiang sumbu $Y$, sumbu $Y$, sumbu $Z$ dan bagian End Effector.Untuk membuat simulasi konstruksi $3 D$ dan pemotongan desain diperlukan Software Autodesk Fusion 360. Berdasarkan laporan yang telah diuraikan, maka kesimpulan proyek akhir ini adalah telah diperoleh hasil produksi komponen mekanik yang diproduksi menggunakan proses pemesinan, yang terdiri atas: rangka, kedudukan sistem transmisi, kedudukan motor, dan kedudukan Grinder. Berdasarkan bentuk rancangan yang telah dibuat, selanjutnya komponen mekanik yang telah diporduksi akan dirakit dengan kompon menjadi yang telah tersedia dipasaran. Mesin dapat bergerak pada masing-masing sumbu pergerakan, yaitu sumbu $X, Y$ dan Z,namun perlu dilakukan kalibrasi pada sistem kontrol agar panjang langkah pergerakan mesin sesuai dengan kode pergerakan yang diinput pada sistem interface (PC). Berdasarkan hasil pengukuran setelah mesin diproduksi, maka didapatkan area kerja mesin ini adalah total biaya yang dibutuhkan untuk membuat serta merakit mesin CNC ini adalah Rp 4.400.000. Merujuk pada website wegstr.com yang merupakan produsen CNC Milling merek Wegstr, harga mesin CNC dengan spesifikasi yang sama adalah 1,996.5 €, jika dalam Rupiah (rate $€ l=R p$ 17.206.20) yaitu $R p$ 34.352.178.35 juta. Maka mesin ini dibuat dengan harga lebih murah dibandingkan dengan harga mesin dipasaran.
\end{abstract}

Kata Kunci: $C N C$, Arduino, CNC Shield.

Abstract

The purpose of making this final project is to make a CNC Milling Router so that it can make a layout directly on the PCB and can be used as a tool for cutting, engraving, marking on wooden objects that can form 3-dimensional objects. The mechanical design of the CNC machine was previously sketched on A3 paper. The design of CNC machine construction includes the base, $Y$ axis, $Y$ axis, $Z$ axis and End Effector section. To make $3 D$ construction simulation and design cutting, Autodesk Fusion 360 software is needed. Based on the report described, the conclusion of this final project is that it has been obtained the results of the production of mechanical components produced using the machining process, which consists of: the frame, the position of the transmission system, the position of the motor, and the position of the Grinder. Based on the design form that has been made, then mechanical components that have been fabricated will be assembled with compounds into those already available in the market. The machine can move on each axis of movement, namely the $X, Y$ and $Z$ axes, but it is necessary to calibrate the control system so that the length of the step in the machine is in accordance with the movement code inputted on the interface system (PC). Based on the results of measurements after the machine is produced, the work area of this machine is obtained, the total cost required to make and assemble this CNC machine is Rp. Referring to the website wegstr.com which is a CNC Milling manufacturer of the Wegstr brand, the price of CNC machines with the same specifications is $1,996.5 €$, if in Rupiah (rate $€ 1=R p$. 17,206.20), that is Rp. 34,352,178.35 million. So this machine is made with a cheaper price compared to the price of the machine in the market

Keywords: CNC, Arduino, CNC Shield.

\section{Introduction}


Pada saat ini, sering kali Mahasiswa mengalami kesulitan dalam pembuatan Layout pada papan PCB. Hal itu dikarenakan pekerjaan-pekerjaan tersebut dilakukan secara manual. Banyak sekali kegiatan yang harus dilakukan dalam pembuatan Layout pada PCB (Printed Circuit Board) secara manual yaitu mulai dari mencetak / mengeprint layout, mengcopy layout tersebut kedalam kertas sticker / kalender, menggosok, menerangi garis layout pada papan PCB agar tidak ada jalur yang putus pada saat proses ferid clorid, serta memferidclorid. Semua kegitan tersebut terkadang menguras waktu dan juga tenaga.

Selain PCB, dalam pengukiran kayu menjadi salah satu motivasi peneliti dalam membuat perancangan ini. Proyek akhir ini dirancang mesin CNC router 3 axis secara sederhana berbasis mikrokontroler. Yang dipadukan dengan bor spindle yang dapat bergerak secara otomatis dengan motor stepper Nema 17 sebagai penggeraknya. Mesin CNC router ini dapat digunakan sebagai alat untuk cutting, engraving, marking pada objek kayu yang dapat membentuk objek 3 dimensi. Mesin dapat digunakan untuk membuat berbagai macam bentuk dengan panjang dan lebar daerah kerja 25 x $35 \mathrm{~cm}$. Desain yang dibuat dapat menggunakan berbagai macam software dengan format file *.gcode. Desain yang telah digambar menggunakan PC (personal computer) dalam bentuk format G-Code akan dikirimkan ke mikrokontroler menggunakan Universal Gcode Sender. Data yang dibaca oleh mikrokontroler memberi logika pada driver motor stepper. Dari data yangditerima oleh driver motor stepper, data digunakan sebagai penggerak ketiga motor stepper, dan terbentuk pola pada bidang sesuai desain.

Dikarenakan hal tersebut, penulis mecoba membuat Perancangan Mesin CNC (Computer Numerical Control) Router dengan Aplikasi GRBL 0.9 Control 3Axis Sistem X,Y,dan Z. Computer Numerical Control / CNC merupakan sistemyang dikontrol oleh computer dengan menggunakan bahasa numeric (dataperintah dengan kode angka, huruf dan symbol) sesuai standar ISO. Sistem kerjateknologi CNC lebih sinkron antara computer dan mekanik bila dibandingkan dengan mesin perkakas sejenisnya, sehingga mesin CNC ini lebih teliti, lebih tepat serta lebih fleksibel. Dengan dimasukkannya layout yang telah dikonversi menjadi G-Code dari computer/laptop kedalam alat tersebut, maka alat tersebut akan bekerja sendiri secara otomatis, membentuk sesuai dengan perintah yang dimasukkan kedalam alat tersebut. Diharapkan dengan dirancangnya alat ini dapat membantu Mahasiswa sehingga kegiatan Mahasiswa dalam pembuatan layout pada PCB dan dengan di buat mesin CNC berbasis mikrokontroller dapat membantu berkembangnya industri kecil dalam bidang ukiran kayu. Karena hanya membutuhkan keterampilan operator dalam pengoperasian alat dan pembuatan desain.dapat menjadi efisien, mudah dan cepat.

Adapun tujuan dari pembuatan proyek akhir ini adalah membuat mesin CNC MILLING ROUTER agar dapat membuat layout secara langsung Pada PCB dan dapat digunakan sebagai alat untuk cutting, engraving, marking pada objek kayu yang dapat membentuk objek 3 dimensi.

\section{Theoritical review}

Dalam proses permesinan digunakan mesin perkakas. Mesin perkakas ini dirancang untuk menggerakkan perkakas potong (cutting tools) guna mendapatkan geometri permukaan benda kerja seperti yang diinginkan. Dalam proses permesinan ada istilah gerak potong dan gerak makan. Gerak potong adalah gerak relatif antara perkakas potong atau pahat dengan benda kerja yang searah dengan arah potongan. Gerak makan ialah gerakan yang mengakibatkan pengulangan gerakan pemotongan setiap putaran atau setiap langkah untuk memastikan kelanjutan operasi pemotongan. Pahat yang bergerak relatif terhadap benda kerja akan menghasilkan geram dan sementara itu permukaan benda kerja secara bertahap akan terbentuk menjadi komponen yang dikehendaki.(Widarto, 2008)

Numerical Control / NC (berarti "kontrol numerik") merupakan sistem otomatisasi mesin perkakas yang dioperasikan oleh perintah yang diprogram secara abstrak dan disimpan dimedia 
penyimpanan sesuai standart ISO, hal ini berlawanan dengan kebiasaan sebelumnya dimana mesin perkakas biasanya dikontrol dengan putaran tangan atau otomatisasi sederhana menggunakan cam. Kata NC sendiri adalah singkatan dalam bahasa Inggris dari kata Numerical Control yang artinya Kontrol Numerik. Mesin NC pertama diciptakan pertama kali pada tahun 40-an dan 50-an, dengan memodifikasi mesin perkakas biasa. Dalam hal ini mesin perkakas biasa ditambahkan dengan motor yang akan menggerakan pengontrol mengikuti titik-titik yang dimasukan kedalam sistem oleh perekam kertas. Mesin perpaduan antara servo motor dan mekanis ini segera digantikan dengan sistem analog dan kemudian komputer digital, menciptakan mesin perkakas modern yang disebut mesin CNC (Computer Numerical Control) yang dikemudian hari telah berevolusi proses desain. (Sandri, 2017) Computer numerical control (CNC) merupakan sebuah mesin yang dapat mendeteksi titik-titik mana saja yang akan dilubangi. Saat ini mesin CNC mempunyai hubungan yang sangat erat dengan program CAD. Mesin-mesin $\mathrm{CNC}$ dibangun untuk menjawab tantangan di dunia manufaktur modern. Dengan mesin $\mathrm{CNC}$, ketelitian suatu produk dapat dijamin hingga $1 / 100 \mathrm{~mm}$ lebih, pengerjaan produk masal dengan hasil yang sama persis dan waktu permesinan yang cepat.

Mesin CNC (Computer Numerical Control) Router juga merupakan salah satu jenis dari mesin CNC yang memiliki 3 fungsi yaitu untuk memotong (cutting), meng grafir (Engraving) dan memberi marka (Marking). Dalam pengerjaannya Mesin CNC Router menggunakan mata bor yang dipasang di kepala motor spindle yang bisa bergerak secara otomatis, sebagai alat untuk cutting - engraving - marking. Mesin CNC Router memiliki pergerakan 3 Axis (Maju - Mundur, Kiri - Kanan, Naik - Turun) (Deprintz,2017). Software (perangkat lunak) adalah data yang diformat dan disimpan secara digital, termasuk program komputer, dokumentasinya, dan berbagai informasi yang bisa dibaca dan ditulis oleh komputer. Dengan kata lain, bagian sistem komputer yang tidak berwujud atau dapat disebut juga sebagai kumpulan program yang berjalan pada komputer. Sebuah program komputer dibuat dari sejumlah instruksi. Instruksi adalah perintah yang diberikan ke komputer untuk melakukan satu hal yang khusus. (Artanto, n.d. 2012)

Hardware (perangkat keras) adalah salah satu komponen dari sebuah komputer yang sifat alat nya bisa dilihat dan diraba secara langsung atau yang berbentuk nyata, yang berfungsi untuk mendukung proses komputerisasi. Hardware dapat bekerja berdasarkan perintah yang telah ditentukan ada padanya, atau yang juga disebut dengan dengan istilah instruction-set. Dengan adanya perintah yang dapat dimengerti oleh hardware tersebut, maka hardware tersebut dapat melakukan berbagai kegiatan yang telah ditentukan oleh pemberi perintah. (McComb, 2001) GRBL adalah salah satu software yang dapat digunakan oleh mesin CNC. Software ini hanya dapat membaca file dengan extention ngc. Dengan menggunakan software ini mesin CNC (Computer Numerical Control) Router dapat bekerja untuk melakukan pengeboran sesuai dengan desaign yang dibuat secara otomatis. (Amal, 2015)

Melalui software GBRL Controller, sistem X, Y, dan Z dapat bergerak sesuai dengan desaign yang telah dibuat. Namun sebelumnya mesin CNC(Computer Numerical Control) Router memerlukan konfigurasi dan kalibrasi terlebih dahulu menggunakan software GRBL 0.9. Konfigurasi dapat dilakukan dengan menggunakan beberapa menu yang tersedia. Tampilan GRBL Controller dapat dilihat pada gambar dibawah ini. 


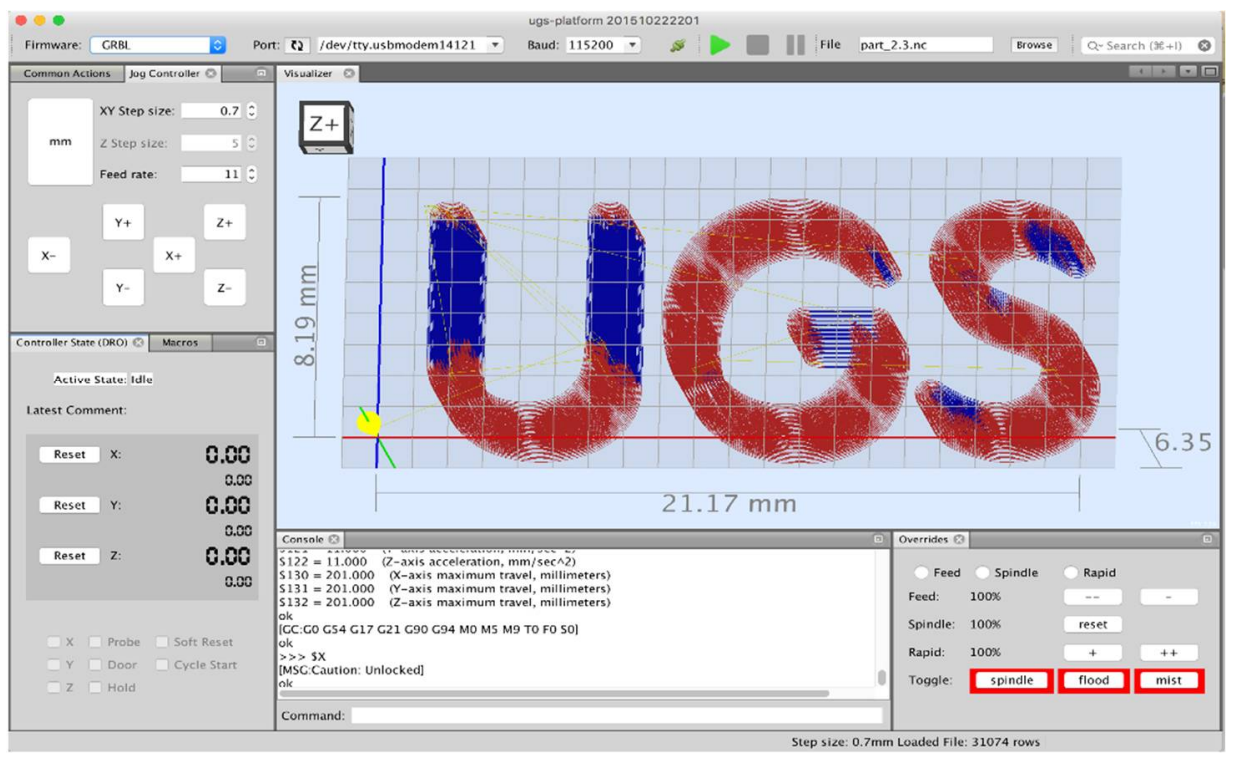

CNC router dilengkapi dengan motor stepper. Motor stepper adalah salah satu jenis motor DC yang dapat berputar pada sudut tertentu pada langkah tetap. Besarnya langkah bervariasi antara $0,9^{\circ}$ hingga $90^{\circ}$.

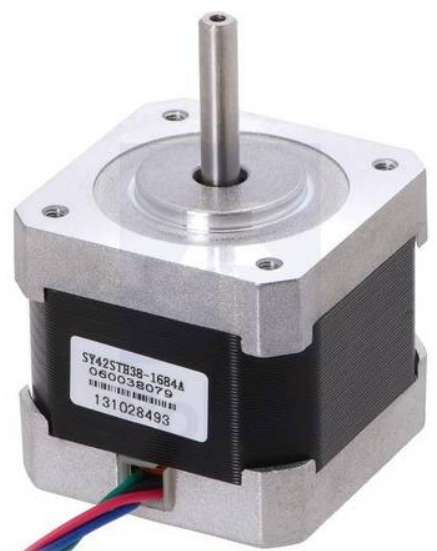

Motor stepper digunakan pada aplikasi yang memerlukan perputaran pada sudut tertentu namun tidak memerlukan feedback dari sensor posisi. Sudut perpindahan diketahui dengan menghitung jumlah langkah yang telah dilakukan Motor stepper merupakan satu-satunya jenis motor DC yang pengendaliannya dapat dilakukan secara open loop. (Rio Dimas, 2015) Motor stepper merupakan salah satu tipe motor yang sangat popular digunakan sebagai peralatan penggerak/pemutar (movement unit/actuator) dalam sistem kontrol otomatis di industri, instrumentasi, bahan printer yang sering kita pakai sehari-hari. Motor stepper dikendalikan sepenuhnya oleh mikrokontroller, karena mikrokontroller hanya mampu memberikan supplay tegangan 5 Volt dan dengan arus sekitar $20 \mathrm{~mA}$, jadi mikrokontroller tidak mampu untuk menggerakkan motor stepper. Maka digunakan driver penggerak untuk mensupplay arus yang dibutuhkan motor stepper tersebut.

Motor stepper merupakan motor DC yang dapat diatur posisinya dengan akurat pada posisi tertentu dan dapat berputar kearah yang diinginkan dengan memberi sinyal - sinyal pulsa dengan pola tertentu. Biasanya motor stepper digunakan untuk aplikasi - aplikasi yang membutuhkan torsi kecil dengan akurasi yang tinggi, seperti pada penggerak head pada flopy disk drive atau pada CDROM (Syahrul, 2016).

Aplikasi penggunaan motor stepper dapat juga di jumpai dalam bidang industri atau untuk jenis motor stepper kecil dapat digunakan dalam perancangan suatu alat mekatronik atau robot. Motor stepper berukuran besar digunakan, misalnya, dalam proses pengeboran logam yang 
menghendaki ketepatan posisi pengeboran, dalam hal ini dilakukan oleh sebuah robot yang memerlukan ketepatan posisi dalam gerakan lengannya dan lain-lain.

Motor stepper merupakan motor DC yang dapat diatur posisinya dengan akurat pada posisi tertentu dan dapat berputar kearah yang diinginkan dengan memberi sinyal - sinyal pulsa dengan pola tertentu. Biasanya motor stepper digunakan untuk aplikasi - aplikasi yang membutuhkan torsi kecil dengan akurasi yang tinggi, seperti pada penggerak head pada flopy disk drive atau pada CDROM (Repository.usu, 2017). Motor driver IC A4988 dipilih sebagai motor driver pada perancangan ini karena tidak boros pin arduino dan mudah cara dioperasikan. Motor driver pada umumnya hanya menaikkan tegangan output dari input arduino, hal ini sangat boros pin pada arduino mengingat tiap motor stepper bipolar memiliki 4 buah kabel. IC A4988 sangat mudah digunakan karena hanya terdapat dua buah input masukkan yakni DIR dan STEP. DIR berfungsi untuk mengubah arah putaran searah jarum jam dan berlawanan jarum jam. STEP berfungsi untuk mengatur kecepatan motor stepper dengan memberikan sinyal HIGH dan LOW dengan jedanya (Pratama, 2015).

IC ini dirancang untuk mengontrol berbagai macam motor stepper, baik motor stepper bipolar, penuh, setengah, atau seperempat. Dengan output hingga $35 \mathrm{~V}$ dan $\pm 2 \mathrm{~A}$. Bentuk asli IC A4988 dapat dilihat pada Gambar dibawah ini IC A4988 memiliki 8 buah kaki yang terdapat pada sisi kanan dan sisi kirinya.

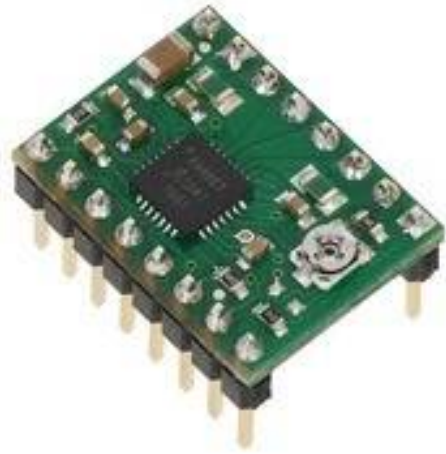

Step per revolution Motor Stepper NEMA 17 adalah 200. Nilai ini dapat dirubah oleh IC A4988 dengan fiturnya yakni microstepping mode.dalam mode ini step per revolution dapat diperbesar dengan faktor pengali. Pengaturan resolusi dari putaran motor terdapat pada pin MS1, MS2 dan MS3 yang dijelaskan pada Tabel di bawah ini (Mercubuana, 2017).

\begin{tabular}{|c|c|c|c|c|}
\hline MS1 & MS2 & MS3 & Microstep Resolution & $\begin{array}{c}\text { Stepper Revolution } \\
\text { pada NEMA 17 }\end{array}$ \\
\hline L & L & L & Full Step & 200 \\
\hline H & L & L & Ha; Step & 400 \\
\hline H & H & L & Quarter Step & 800 \\
\hline H & H & L & Eighth Step & 1600 \\
\hline H & H & H & Sixteenth Step & 3200 \\
\hline
\end{tabular}

Uno Arduino adalah board berbasis mikrokontroler pada ATmega328 .Board ini memiliki 14 digital input / output pin (dimana 6 pin dapat digunakan sebagai output PWM), 6 input analog, 16 $\mathrm{MHz}$ osilator kristal, koneksi USB, jack listrik tombol reset. Pin-pin ini berisi semua yang diperlukan untuk mendukung mikrokontroler, hanya terhubung ke komputer dengan kabel USB atau sumber tegangan bisa didapat dari adaptor AC-DC atau baterai untuk menggunakannya. 


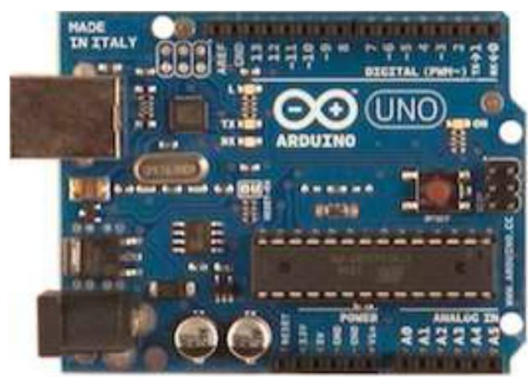

Untuk deskripsi arduino uno dapat dilihat pada tabel berikut ini :

\begin{tabular}{|l|l|}
\hline \multicolumn{1}{|c|}{ Mikrokontroler } & \multicolumn{1}{c|}{ Atmega328 } \\
\hline Operasi Voltage & $5 \mathrm{~V}$ \\
\hline Input Voltage & $7-12 \mathrm{~V}$ (Rekomendasi) \\
\hline Input Voltage & $6-20 \mathrm{~V}$ (Limits) \\
\hline I/O & 14 Pin (6 Pin untum PWM) \\
\hline Arus & $50 \mathrm{~mA}$ \\
\hline Flash Memory & $32 \mathrm{~KB}$ \\
\hline Bootloader & SRAM 2 KB \\
\hline EEPROM & $1 \mathrm{~KB}$ \\
\hline Kecepatan & $16 \mathrm{hz}$ \\
\hline
\end{tabular}

\section{Design}

Perancangan mekanik mesin $\mathrm{CNC}$ ini sebelumnya dibuat sketsa gambar pada kertas $\mathrm{A} 3$. Perancangan konstruksi mesin CNC meliputi bagian dasar, tiang sumbu Y, sumbu Y, sumbu Z dan bagian End Effector.Untuk membuat simulasi konstruksi 3D dan pemotongan desain diperlukan Software Autodesk Fusion 360 seperti yang terlihat pada Gambar dibawah ini. Mesin CNC ini memiliki tiga bagian utama yaitu konstruksi sumbu X, konstruksi sumbu Y dan konstruksi sumbu Z.

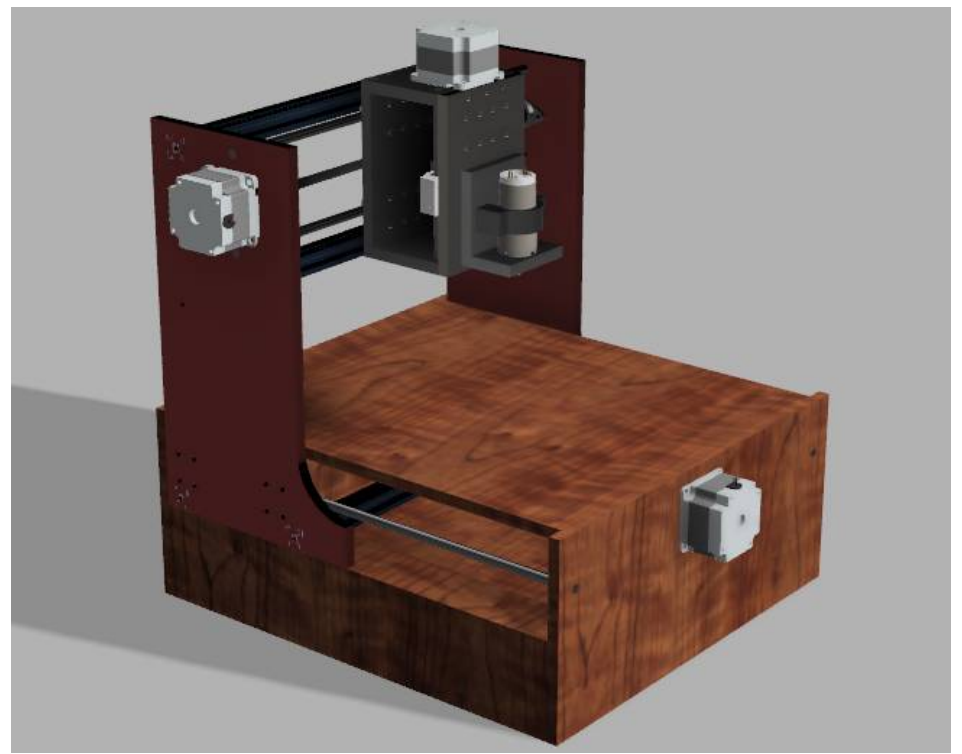

Sistem sumbu X merupakan bagian yang bergerak berdasarkan sumbu X yaitu bergerak horizontal ke kanan dan ke kiri. Sistem pergerakan sumbu ini menggunakan threaded rod berdiameter $8 \mathrm{~mm}$ dan baut. Coupler digunakan sebagai sambungan antara shaft motor denganthreaded rod. Bagian yang bergerak pada sumbu X didisisipkan Nut atau Baut,prinsipnya ketika motor berputar maka baut akan bergerak ke kirimaupun kekanan karena ulir pada threaded rod tersebut. 
Jarak antar ulir pada threaded roda adalah $0,8 \mathrm{~mm}$, jadi satu putaran penuh motor stepper menghasilkan jarak sejauh nilai tersebut. Untuk memperoleh jarak $1 \mathrm{~mm}$ maka step per milimeter yang harus dihasilkan pada motor stepper adalah :

$$
\begin{aligned}
& \text { Jumlah step } / \mathrm{mm}=\frac{1}{\text { Jarak antara alur }} \times \text { Jumlah Step satu lingkaran penuh } \\
& \text { Jumlah step } / \mathrm{mm}=\frac{1}{0,8} \times 200=250 \text { step } / \mathrm{mm}
\end{aligned}
$$

Sistem sumbu Y merupakan bagian yang bergerak berdasarkan sumbu Y yaitu bergerak horizontal kearah depan dan belakang. Sistem pergerakan sumbu ini menggunakan threaded rod berdiameter $8 \mathrm{~mm}$ dan baut. Coupler digunakan sebagai sambungan antara shaft motor dengan threaded rod. Bagian yang bergerak pada sumbu X didisisipkan Nut atau Baut, prinsipnya ketika motor berputar maka baut akan bergerak ke kiri maupun ke kanan karena ulir pada threaded rod tersebut.

Jarak antar ulir pada threaded roda adalah $0,8 \mathrm{~mm}$, jadi satu putaran penuh motor stepper menghasilkan jarak sejauh nilai tersebut. Untuk memperoleh jarak $1 \mathrm{~mm}$ maka step per milimeter yang harus dihasilkan pada motor stepper adalah :

$$
\begin{aligned}
& \text { Jumlah step/ } m m=\frac{1}{\text { Jarak antara alur }} \times \text { Jumlah Step satu lingkaran penuh } \\
& \text { Jumlah step/ } \mathrm{mm}=\frac{1}{0,8} \times 200=250 \text { step } / \mathrm{mm}
\end{aligned}
$$

Sistem sumbu $\mathrm{Z}$ merupakan bagian yang bergerak berdasarkan sumbu $\mathrm{Z}$ yaitu bergerak vertikal kearah atas dan bawah. Sistem pergerakan sumbu ini menggunakan threaded rod berdiameter $8 \mathrm{~mm}$ dan baut. Coupler digunakan sebagai sambungan antara shaft motor dengan threaded rod. Bagian yang bergerak pada sumbu X didisisipkan Nut atau Baut, prinsipnya ketika motor berputar maka baut akan bergerak ke kiri maupun ke kanan karena ulir pada threaded rod tersebut.

Jarak antar ulir pada threaded roda adalah $0,8 \mathrm{~mm}$, jadi satu putaran penuh motor stepper menghasilkan jarak sejauhnilai tersebut. Untuk memperoleh jarak $1 \mathrm{~mm}$ maka step per milimeter yang harus dihasilkan pada motor stepper adalah :

$$
\begin{aligned}
& \text { Jumlah step } / \mathrm{mm}=\frac{1}{\text { Jarak antara alur }} \times \text { Jumlah Step satu lingkaran penuh } \\
& \text { Jumlah step/ } \mathrm{mm}=\frac{1}{0,8} \times 200=250 \text { step } / \mathrm{mm}
\end{aligned}
$$

Dalam pembuatan mesin CNC ini tentunya tidak terlepas dari adanya sistem elektrikal. Oleh karena itu untuk mendapatkan sistem elektrikal sesuai kebutuhan maka perlu dilakukan perancangan. Adapun perancangan disini adalah pemasangan power supply, pembuatan rangkaian motor driver untuk motor stepper dengan IC A4988, pemasangan motor stepper dan komponenkomponen pendukung lainya. Pada gambar berikut adalah Blok diagram sistem elektrikal pada mesin CNC 


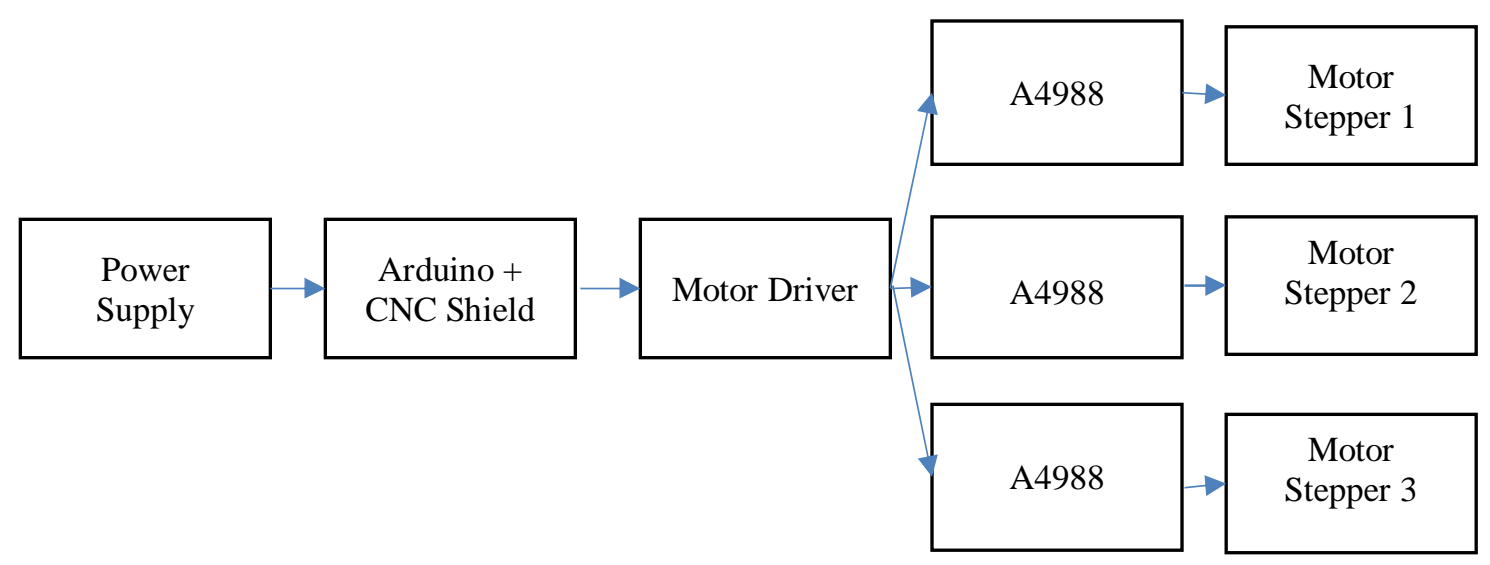

Dalam perancangan prototype mesin CNC ini diperlukan Arduino Programming Tools untuk melakukan pemrograman Arduino dan software GBRL Controller untuk melakukan konfigurasi sistem X, Y, dan Z dan kalibrasi motor stepper pada prototype mesin CNC.

Arduino digunakan untuk mengontrol putaran tiga buah motor stepper melalui IC A4988. Pemrograman pada Arduino dapat menggunakan sebuah software khusus yaitu Arduino Programming Tools. Program yang dibuat melalui Arduino Programming Tools dapat dilihat pada Gambar dibawah ini

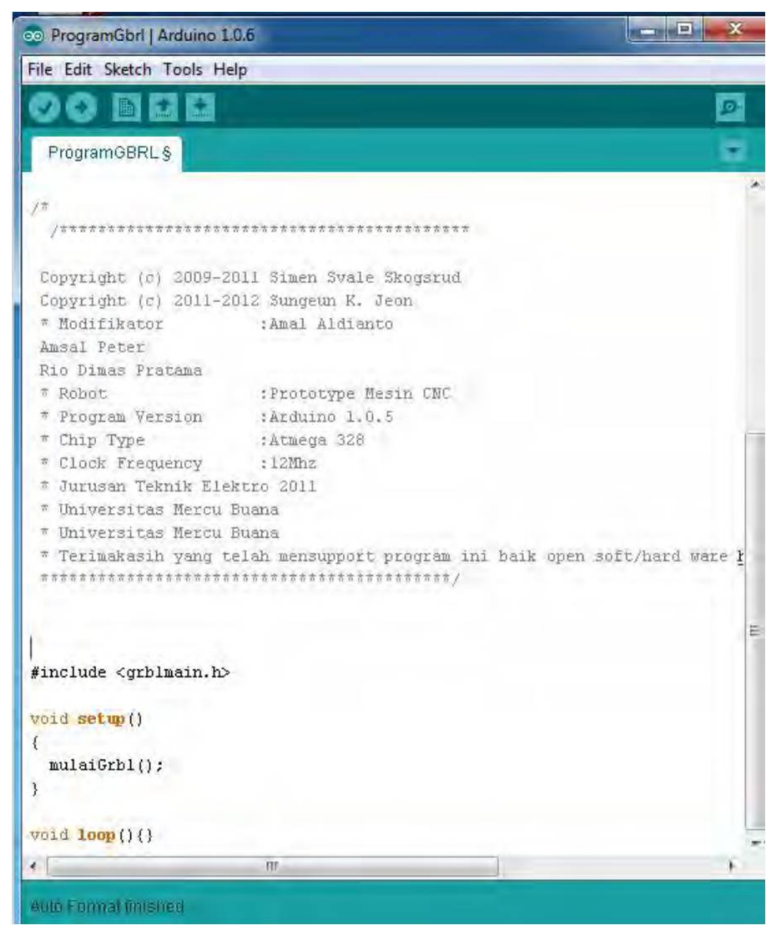

Software pada sistem kontrol merupakan perangkat lunak (program komputer) yang digunakan untuk mengontrol mesin CNC 3-axis. Software tersebut selanjutnya akan di-install pada perangkat komputer dan bertindak sebagai interface. Interface merupakan perangkat lunak yang berfungsi mengkomunikasikan semua perintah dari end user sehingga mampu dibaca dengan baik oleh semua hardware. Dengan adanya interface mesin CNC akan bergerak sesuai dengan program yang telah didesain sebelumnya.

Pada penelitian ini, yang digunakan sebagai interface adalah perangkat lunak Universal GCode Sender. Adapun tampilan program Universal G-Code Sender diperlihatkan pada Gambar bawah ini: 
ưs 1001.nc - Universal Gcode Plattorm (Version 2.0 [nighty] / Jul 15, 2018)

$-\quad x \quad x$

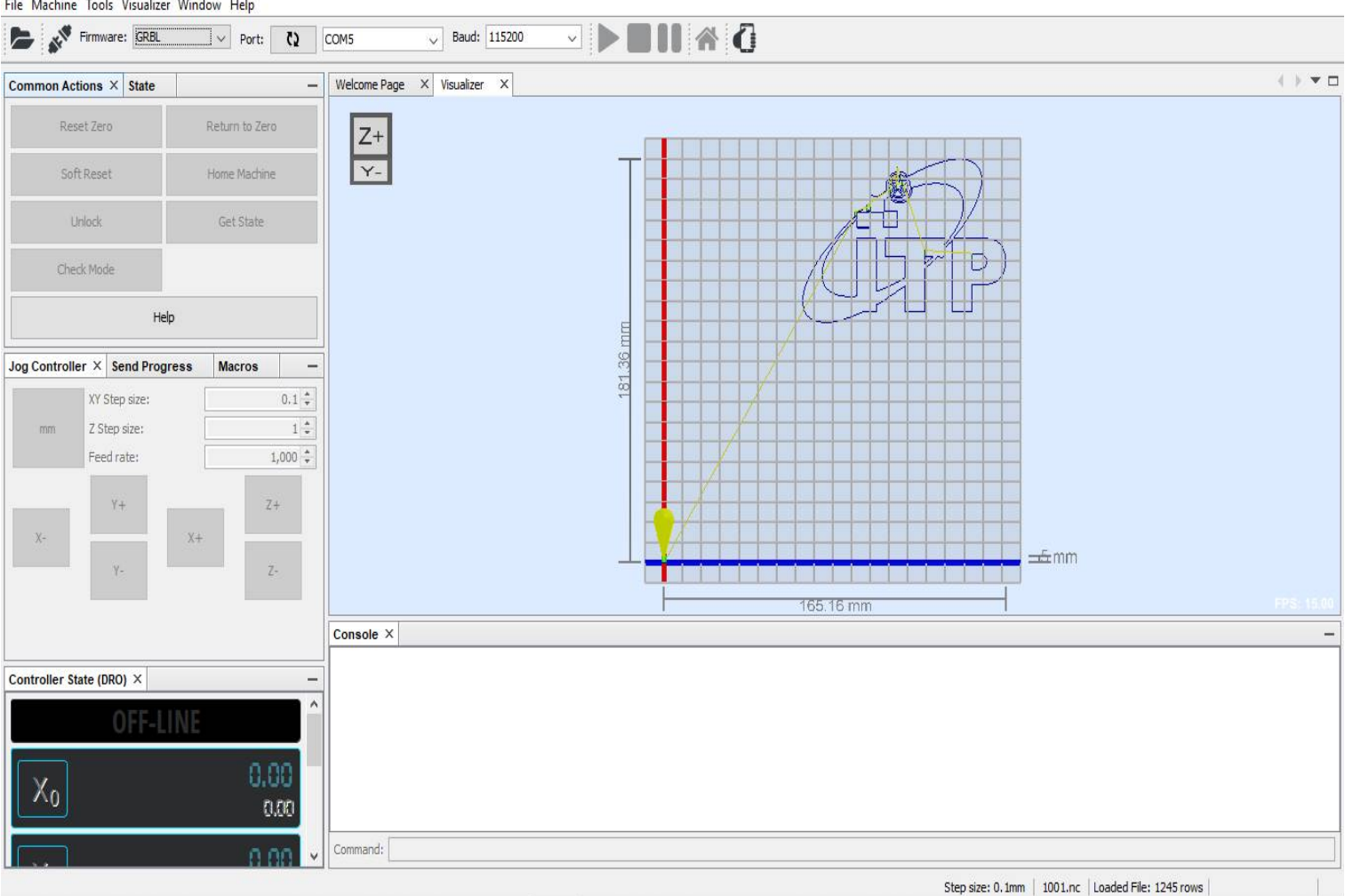

\section{Project Making}

Berikut adalah flow chart dari pembuatan mesin router CNC Milling :

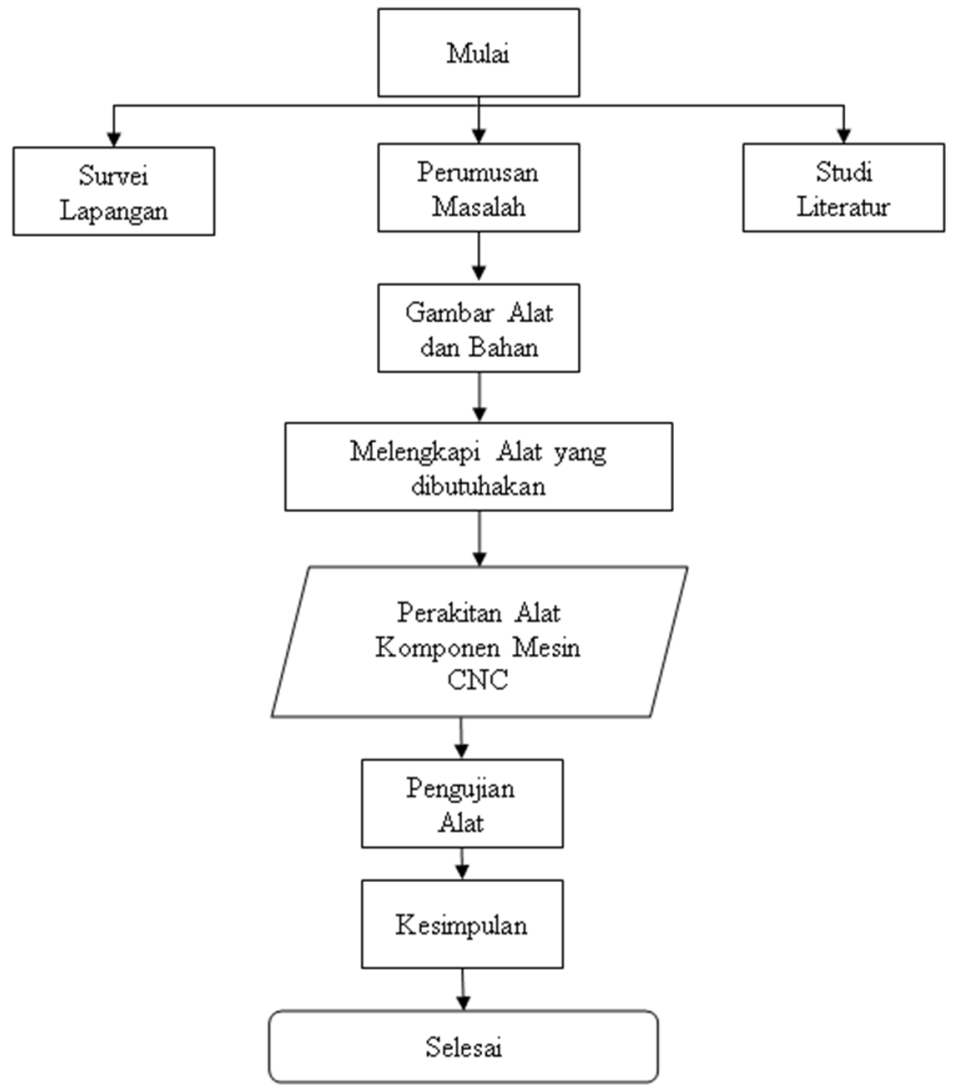


Untuk pencetakan penahan komponen-komponen Mesin CNC Milling Router ini menggunakan mesin 3D Printer dengan bahan Filament PLA+.

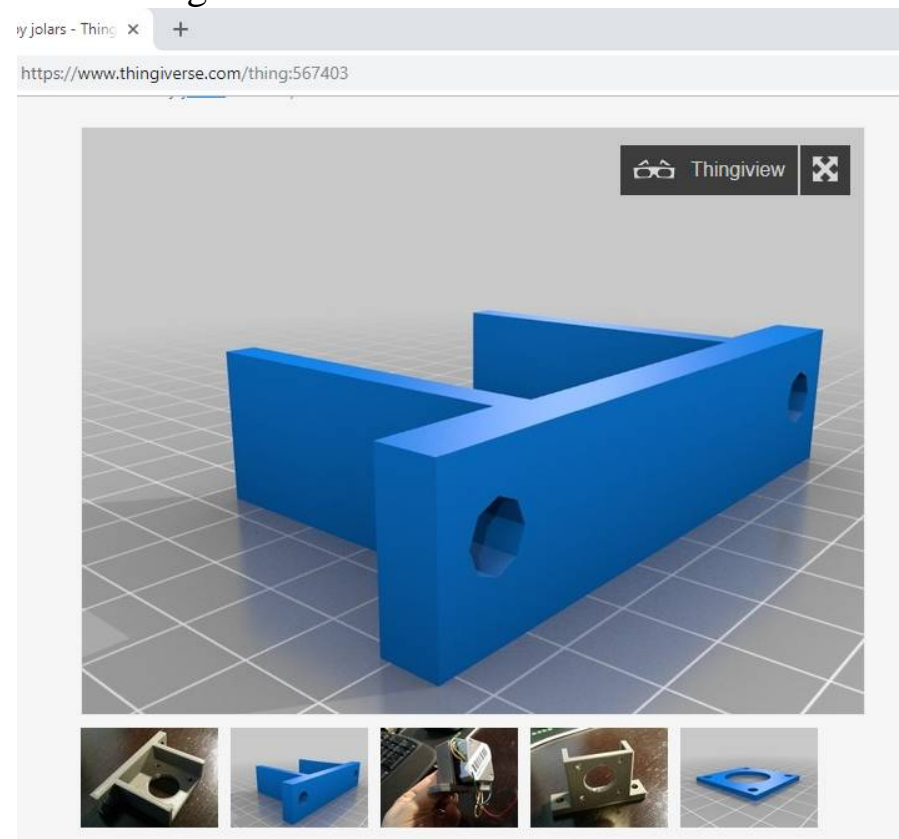

Percetakan penahan komponen-komponen Mesin CNC Milling Router menggunakan mesin 3D Printer dengan desain diambli dari situs website www.thingiverse.com yang merupakan situs OpenSource serta memiliki berbagai macam desain tentang 3D Printer. Desain tersebut didownload serta diproses dengan mencetak dengan mesin 3D Printer.

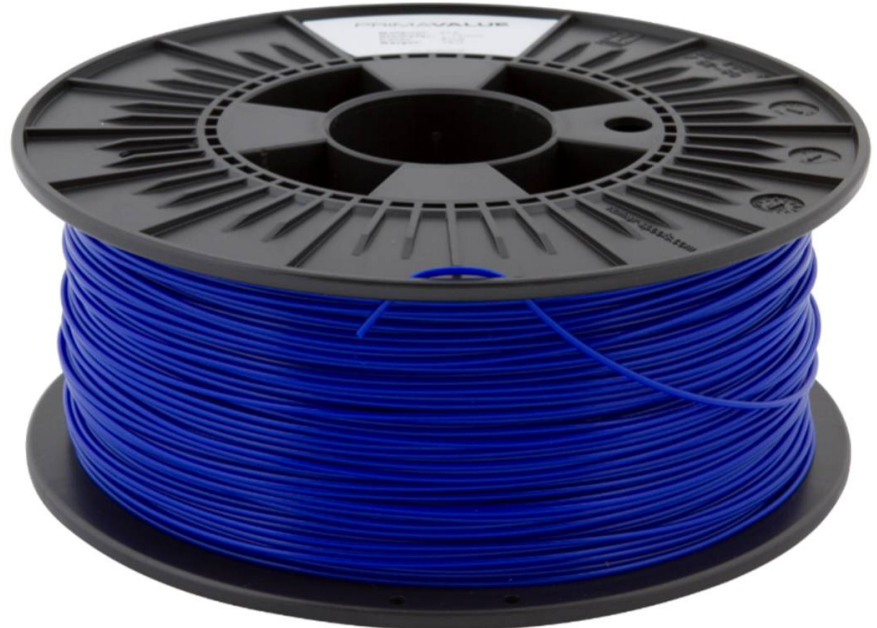

Berbagai jenis 3D filament yang dapat digunakan pada printer 3D, namun jenis yang paling umum yaitu ABS dan PLA. PLA (Polylactic Acid) merupakan bahan biodegradablethermoplastic aliphatic polyester yang terbuat dari tepung jagung, tapioka atau tebu. Filament PLA relatif aman digunakan. Hasil cetak PLA lebih mengkilat dan tidak rawan warping (ujung cetak model melengkung ke atas) dibanding ABS.

PLA Filament menggunakan teknologi terbaru yang memberikan ketahanan yang panjang dan kualitas terjamin. Packaging PLA sudah divakum dan dilengkapi dengan silica gel untuk memperpanjang umur pemakaian filament. PLA mudah menyerap kelembaban, maka disarankan untuk menyimpan PLA di wadah kedap udara dengan dilengkapi silica gel. 3D Filament yang dipasarkan oleh DataPrint berjenis PLA bisa dipakai oleh semua Printer 3D dengan diameter nozzle $1.75 \mathrm{~mm}$ yang bisa digunakan oleh semua 3D Printer. 


\section{Discussion result}

Berdasarkan hasil dari proses produksi mesin serta perakitannya, maka dihasilkan mesin CNC dengan bentuk terlihat seperti pada Gambar di bawah ini:

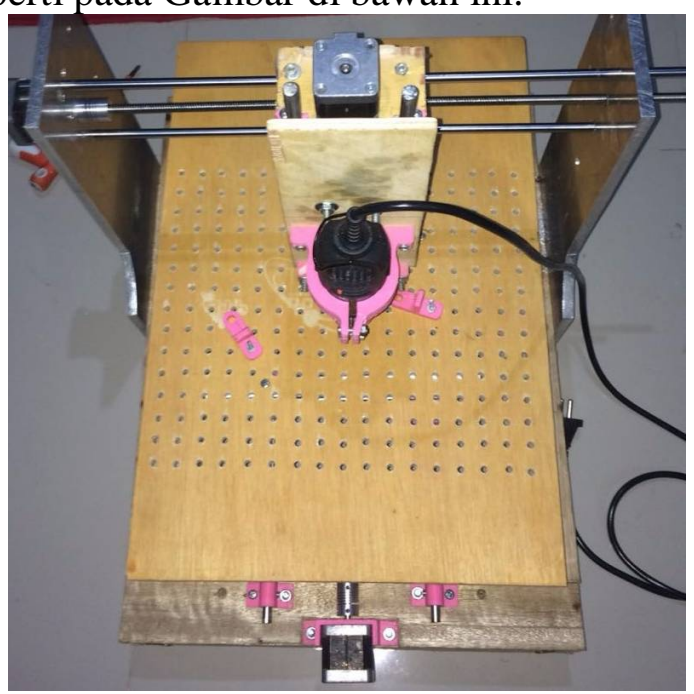

\section{Hasil Pembuatan dan Perakitan Mesin CNC Milling Router Tampak Atas}

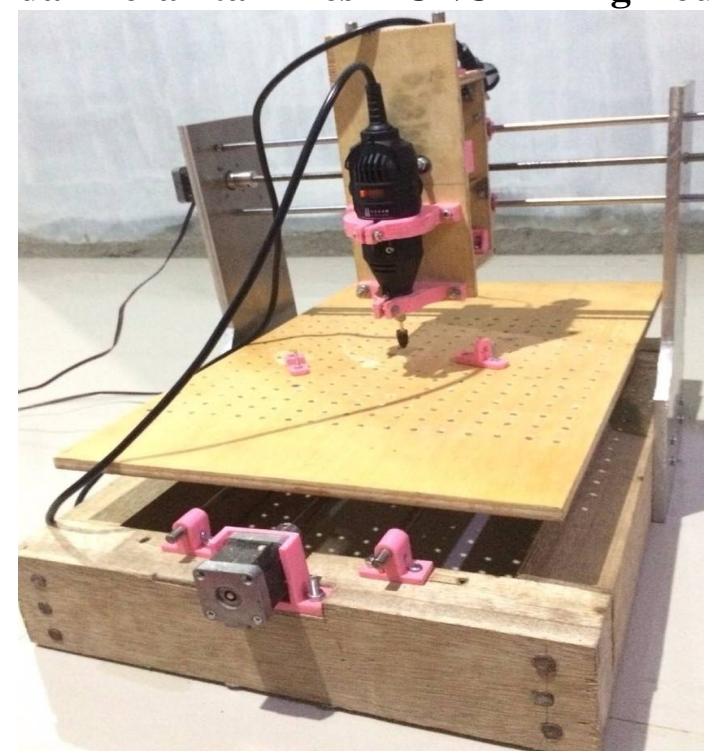

Hasil Pembuatan dan Perakitan Mesin CNC Milling Router Tampak Depan

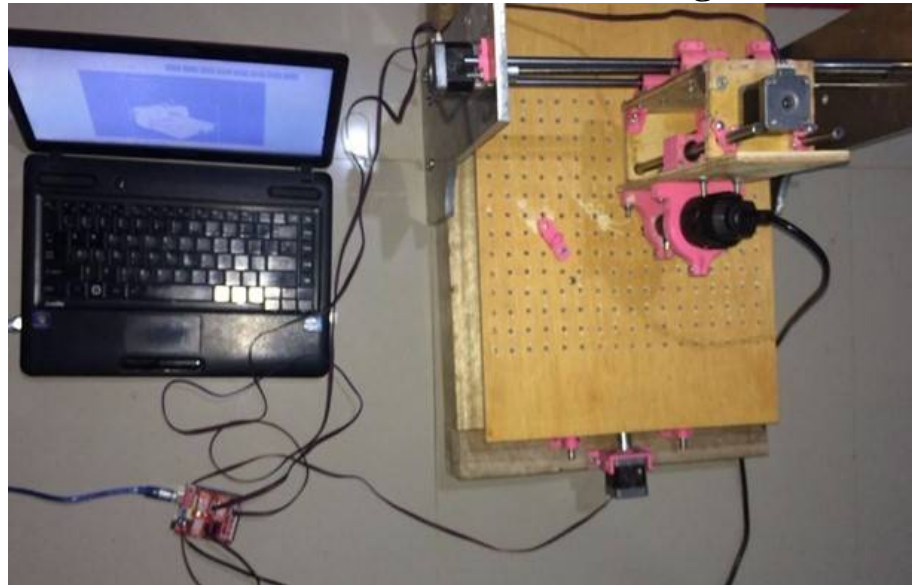

\section{Hasil Pembuatan dan Perakitan Mesin CNC Milling Router}

Terdapat sedikit perbedaan dimensi terhadap desain dari perancangan mesin ini. Perbedaan itu terletak pada rangka. Hal ini menyebabkan terdapat perbedaaan dimensi rangka terhadap desain 
rancangan mesin sebelumnya. Maka, sebaiknya dilakukan pengujian lanjutan mengenai pengaruh perbedaan dimensi yang berbeda dengan desain rancangan terhadap kinerja mesin tersebut.

\section{Conclusion} berikut :

Berdasarkan laporan yang telah diuraikan, maka kesimpulan proyek akhir ini adalah sebagai

1. Telah diperoleh hasil produksi komponen mekanik yang diproduksi menggunakan proses pemesinan, yang terdiri atas: rangka, kedudukan sistem transmisi, kedudukan motor, dan kedudukan Grinder.

2. Berdasarkan bentuk rancangan yang telah dibuat, selanjutnya komponen mekanik yang telah diporduksi akan dirakit dengan kompon menjadi yang telah tersedia dipasaran.

3. Mesin dapat bergerak pada masing-masing sumbu pergerakan, yaitu sumbu X, Y dan $\mathrm{Z}$,namun perlu dilakukan kalibrasi pada sistem kontrol agar panjang langkah pergerakan mesin sesuai dengan kode pergerakan yang diinput pada sistem interface (PC).

4. Berdasarkan hasil pengukuran setelah mesin diproduksi, maka didapatkan area kerja mesin ini adalah:

a. Panjang area kerja sumbu- $\mathrm{x}=250 \mathrm{~mm}$

b. Panjang area kerja sumbu-y= $300 \mathrm{~mm}$

c. Panjang area kerja sumbu- $\mathrm{z}=120 \mathrm{~mm}$

5. Total biaya yang dibutuhkan untuk membuat serta merakit mesin $\mathrm{CNC}$ ini adalah $\mathrm{Rp}$ 4.400.000. Merujuk pada website wegstr.com yang merupakan produsen CNC Milling merek Wegstr, harga mesin CNC dengan spesifikasi yang sama adalah 1,996.5 €, jika dalam Rupiah (rate $€ 1=R p$ 17.206.20) yaitu Rp 34.352.178.35 juta. Maka mesin ini dibuat dengan harga lebih murah dibandingkan dengan harga mesin dipasaran.

\section{Suggestion}

Disarankan agar alat Mesin CNC Milling Router ini dapat lebih dikembangkan oleh mahasiswa selanjutnya sepert penambahan sumbu axis menjadi 4 atau 5 dengan spesifikasi yang lebih lengkap.

\section{References}

Amal, A. (2015). Prototype Mesin CNC Berbasis Arduino Uno Dengan Software GBRL Controller. S1 Thesis, Universitas Mercu Buana.

Artanto, D. (n.d.). 60 Aplikasi PLC-mikro: menggunakan mikrokontroler PIC16F877 dan ATmega8 (Arduino Severino).

McComb, G. (2001). The Robot Builder's Bonanza Second Edition. United States of America: McGraw-Hill.

Rio Dimas, P. (2015). Prototype Mesin CNC Dengan Pengeboran Otomatis Untuk Pembuatan PCB. S1 Thesis, Universitas Mercu Buana.

Sandri. (2017). CNC (Computer Numerical Control) Engraver. Bengkulu: Planet Elektrik.

Widarto. (2008). Teknik Pemesinan untuk SMK, Jilid 1. Jakarta: Direktorat Pembinaan Smk. 